Coзаfва T.X., РаХаев Х.М., БакКУев Э.С

ИНФОРМАЦИОННО-КОММУНИКАЦИОННЫЕ ТЕХНОЛОГИИ КАК ФАКТОР ПОВЫШЕНИЯ КОНКУРЕНТОСПОСОБНОСТИ РЕГИОНА

УДК: 338:004.9

СОЗАЕВА ТАНЗИЛЯ ХАКИМОВНА

к.э.н., доцент, заведующий научно-исследовательской лабораторией «Центр финансовых исследований» ФББОУ ВО Кабардино-Балкарский ГАУ, e-mail: sozaytanzilya@yandex.ru

РАХАЕВ ХАДИС МАГОМЕДОВИЧ

д.э.н., профессор, профессор кафедры управления ФГБОУ ВО Кабардино-Балкарский ГАУ, e-mail: r3bizengin@mail.ru

БАККУЕВ ЭЛЬДАР САФАРОВИЧ

д.э.н., профессор, профессор кафедры управления ФГБОУ ВО Кабардино-Балкарский ГАУ, e-mail:bakkuev@mail.ru

DOI:10.26726/1812-7096-2019-11-82-88

\title{
ИНФОРМАЦИОННО-КОММУНИКАЦИОННЫЕ ТЕХНОЛОГИИ КАК ФАКТОР ПОВЫШЕНИЯ КОНКУРЕНТОСПОСОБНОСТИ РЕГИОНА 1
}

\begin{abstract}
Аннотауия. Цель работы. В статье рассматриваются направления перестройки экономики в системе нового технологического уклада, основной структурой которого становятся искусственный интеллект (ИИ) и информационно-коммуникационные технологии (ИКТ). Метод проведения работы. Проведен статистический анализ изменений, происшедших в экономике как региона, так и страны в целом в условиях иифровизации. Результаты. Выявлены направления структурной перестройки экономики в системе нового технологического уклада в условиях формирования ииффовой экономики. В различных источниках по-разному трактуется и оченивается не только сама цифровая экономика, но и ее роль в развитии региональных экономик, а также мировой экономики. Многие теоретические и методологические вопросы ииифровизаиии и формирования иифрровой экономики как на региональном, так и на планетарном уровне получили достаточное освещение в исследованиях зарубежных и отечественных ученых. Поэтому можно говорить если не о завершенности теоретико-методологической базы, то по меньшей мере о наличии добротной теоретической и методологической основы для исследования проблем иифровизации и иифровой экономики. Однако остаются не решенными многие прикладные практические вопросы, среди которых наиболее значимы: оценка объема и доли циифровой экономики в общей экономике, влияние иифровизащии и циифровой экономики на основные макроэкономические показатели (рост, производительность, эффективность и т. д.) и др. В связи с этим представляется, что одной из важных прикладных задач является оценка емкости цифрового рынка в целом по начиональному хозяйству, а также в приложении к различным отраслям и территориям. Область прн-

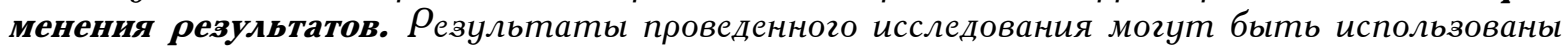
при анализе состояния и прогнозировании спроса на информационно-коммуникационные технологии в экономике региона. Выводы. Делается вывод, во-первых, жестко привязать основные макроэкономические показатели развития региональных экономик и развитие цифрового рынка, его основных структур и элементов. Последнее делается с иелью стимулирования циировизаџии наџионального (регионального) хозяйства и расширения рынка в целом за счет включения в него нового иифрового продукта. Во-вторых, увеличить расходы на ИКТ, а внутри данных расходов по таким статьям, которые стимулировали бы развитие производства собственной циифровой продукции, а значит, развитие внутреннего цифрового рынка.
\end{abstract}

Ключевые слова: регион, иифровая экономика, искусственный интеллект, информационно-коммуникационные технологии.

\footnotetext{
${ }^{1}$ Статья подготовлена при финансовой поддержке гранта РФФИ проект № 19-010-00289 А «Исследование и разработка методов и моделей конкурентного развития регионов в новой экономике».
} 
SOZAEVA TANZILYA KHAKIMOVNA

Ph. D., associate Professor, head of the research laboratory "Center for financial research" FSBEI HE Kabardino-Balkarian SAU, e-mail: sozaytanzilya@yandex.ru

RAKHAEV KHADIS MAGOMEDOVICH doctor of Economics, $\rho_{\text {rofessor, }} \rho_{\text {rofessor of the Department of management }}$ FSBEI HE Kabardino-Balkarian SAU, e-mail: r3bizengin@mail.ru

BAKKUEV ELDAR SAFAROVICH doctor of Economics, $P_{\text {rofessor, }} P_{\text {rofessor of the Department of management }}$ FSBEI HE Kabardino-Balkarian SAU, e-mail:bakkuev@mail.ru

\title{
INFORMATION AND COMMUNICATION TECHNOLOGIES AS A FACTOR OF INCREASING THE REGION'S COMPETITIVENESS
}

\begin{abstract}
Purpose of work. The article considers the directions of economic restructuring in the system of a new technological order, the main structure of which is artificial intelligence $(A I)$ and information and communication technologies (ICT). The method of carrying out the work. A statistical analysis of changes that have occurred in the economy of both the region and the country as a whole in the conditions of digitalization is carried out. Results. The directions of structural adjustment of the economy in the system of a new technological order in the conditions of formation of the digital economy are revealed. Various sources interpret and evaluate not only the digital economy itself, but also its role in the development of regional economies, as well as the world economy, in different ways. Many theoretical and methodological issues of digitalization and the formation of the digital economy at both the regional and global levels have received sufficient coverage in the research of foreign and domestic scientists. Therefore, we can speak, if not about the completeness of the theoretical and methodological base, then at least about the existence of a sound theoretical and methodological basis for the study of the problems of digitalization and the digital economy. However, many applied practical issues remain unresolved, among which the most significant are the assessment of the volume and share of the digital economy in the overall economy, the impact of digitalization and the digital economy on the main macroeconomic indicators (growth, productivity, efficiency, etc.), and others. In this regard, it seems that one of the important applied tasks is to assess the capacity of the digital market as a whole for the national economy, as well as in the application to various industries and territories. The scope of the results. The results of the research can be used to analyze the state and forecast the demand for information and communication technologies in the economy of the region. Conclusions. The conclusion is made, first, to rigidly link the main macroeconomic indicators of the development of regional economies and the development of the digital market, its main structures and elements. The latter is done in order to stimulate the digitalization of the national (regional) economy and expand the market as a whole by including a new digital product in it. Secondly, we need to increase spending on ICT, and within these expenditures on items that would stimulate the development of our own digital production, and therefore the development of the internal digital market.
\end{abstract}

Keywords: region, digital economy, artificial intelligence, information and communication technologies.

Введение. Информация как фактор экономического развития и формирования экономики всегда присутствовала в экономике, т. к. выступала фактором, который использовали различные экономические агенты. Но при этом отличие новой эпохи заключается в том, что если в прошлые эпохи информация выступала некоторым всеобщим условием, то теперь она является концептуальным фактором развития. Выдвижение информации в ранг контекстуального ресурса экономики связано с так называемыми информационными технологиями, т. е. техно- 
Созаева Т.Х., РаХаев Х.М., БакКУев Э.С.

ИНФОРМАЦИОННО-КОММУНИКАЦИОННЫЕ ТЕХНОЛОГИИ КАК ФАКТОР ПОВЫШЕНИЯ КОНКУРЕНТОСПОСОБНОСТИ РЕГИОНА

логиями производства, хранения, передачи, обмена и потребления информации. В статье рассматривается перевод информации в экономический ресурс, чтобы информацию можно было потреблять и производить с коммерческой целью, т. е. делать информацию товаром.

Теоретическую и методологическую основу настоящего исследования составляют работы зарубежных $[8,12,16,17,18]$ и отечественных ученых-экономистов $[1,2,3,4,7]$ в области определения емкости рынка. В то же время в виду особенности предмета и объекта исследования основные категории, понятия, а также методики исчисления отдельных характеристик цифрового рынка заимствуются из Стратегии инновационного развития Российской Федерации [14], Указа Президента РФ «О Стратегии развития информационного общества в Российской Федерации на 2017-2030 годы» [15], программных документов Министерства цифрового развития, связи и массовых коммуникаций РФ.

Методы исследования. Информация как фактор экономики и экономический фактор породила огромный сегмент (сектор) в экономиках. Основу данного сегмента (сектора) составляет производство и потребление информации с соответствующими институциями: технологией, коммуникациями, агентами и проч. Важным институтом данного сегмента выступает цифровой рынок - рынок продавцов и покупателей цифровой продукции, на котором: вопервых, реализуется специфический товар - цифровой продукт, во-вторых, в качестве продавцов и покупателей выступают специфические экономические агенты. С одной стороны, это традиционные покупатели и нетрадиционные продавцы, а с другой - это традиционные технологии рынка: спрос, предложение, цена, эластичность и проч. Есть в нем также и технологические особенности, которые в меньшей степени встречаются, например, на продовольственном рынке. Это одновременно и рынок товаров, и рынок услуг. На наш взгляд, одним из базовых параметров рынка является емкость рынка. Емкость рынка нами исследуется применительно к цифровому рынку. Базовым понятием в настоящем исследовании выступает емкость цифрового рынка. Под емкостью рынка понимают возможность при неизменных ценах, логистики и прочих производственно-технологических и коммерческих условиях поглотить определенный объем товаров и услуг потребителем [1]. Иными словами, емкость рынка - это спрос. Спрос в строгом определении - денежное выражение потребности или возможности покупки товаров и услуг [7]. Емкость рынка - величина непостоянная, а динамичная. На ее динамику (объем) оказывают влияния: численность потребителей, их доходы, цены, сопряженные товары, психология покупателя-потребителя и проч.

Исходя из высказанных положений определим «емкость цифрового рынка» как «спроса на цифровые продукты или продукты цифрового сегмента экономики» [16]. Это возможность потребления цифровых продуктов населением и промежуточными потребителями. Население как один из субъектов емкости рынка цифровой продукции потребляет последнюю в нескольких субстанциях:

- как аудио- и видеоуслугу;

- как приложение к персональным компьютерам (например, приобретение антивирусных программ для работы компьютера или же различных версий Windows и т. п.);

- программных и прочих сервисных продуктов к своим мобильным средствам связи;

- базы данных [5].

Население выступает своеобразным чистым потребителем данной продукции. По нашим подсчетам, доля населения в емкости цифрового рынка составляет не более $10 \%$. Другой субъект емкости цифрового рынка - предприятия, организация и прочие экономические агенты, обозначенные как промежуточные потребители или продавцы [2]. Всех их объединяет то, что они выступают хозяйствующими субъектами, т. е. приобретают продукцию в виде сырья и производят продукцию для последующей реализации. Поэтому они лишь частично потребляют данную продукцию в отличие от населения или конечных потребителей.

В данном контексте интересно то, что предприятия, как и население, могут выступать в цифровой экономике не только как потребители, но и как производители, имея этот статус одновременно [18]. Феномен заключается в том, что лучше всего это демонстрируют сельскохозяйственные предприятия различных форм собственности и типов хозяйствования. Так, любое сельскохозяйственное предприятие в качестве одного из основных элементов содержит землю. Земля и как средство производства, и как предмет труда, и как товар различается по 
своим производительным признакам: местоположению, конфигурации, а главное - по плодородию и т. д. При этом имеется рынок земли, т. е. где земля продается и покупается. В отличие от других товаров сельскохозяйственные земли (и земли сельскохозяйственного назначения) продаются и покупаются не сами по себе, а в виде прав собственности. Но при этом на рынке важна потребительская стоимость, т. е. сколько стоит земля, определяется ее производительной способностью, т. е. качеством земли. Эти параметры земли учитываются в специальных кадастровых картах, которые в оцифрованном виде и представляют фактически землю как товар. Покупателю важно иметь не только индикаторы плодородия почвы, местоположения участка и т. д., но также и его продуктивность, т. е. что даст данный участок земли. Эти особенности представляют урожайность. Поэтому такая характеристика должна быть оцифрована и содержаться в специальной карте участка. Аналогично должны быть описаны характеристики и в животноводстве, т. е. на всех животных имеются электронные чипы, в которых содержатся данные: родословная, возраст, потомство и прочие признаки конкретной особи.

В основе настоящего исследования лежат определенные догмы и постулаты. Одной из базовых догм (постулат) выступает то, что динамика национального хозяйства (экономики) прямо пропорциональна внедрению в нее инновационных технологий и технико-технологических нововведений. При этом в зависимости от господствующего в национальном хозяйстве технологического уклада (ТУ) инновационный и нововведенческий характер имеют, во-первых, разные технологии и технические устройства, во-вторых, внедрение инноваций и нововведений оказывает прямое влияние на динамику (макроэкономические параметры) развития различных объектов -от домашних хозяйств до национального хозяйства в целом. Поэтому, например, в одной экономике замена лошадиной силы (лошади, вола и т.п.) на трактор, машину представляет инновации и нововведения, тогда как в другой оно не является даже нововведением. Наоборот, внедрение компьютеров и иных ИКТ-продуктов для одних экономик представляет предмет забавы, тогда как для других объективно необходимый технологический продукт, без которого останавливается технологический процесс. В условиях пятого технологического уклада решающее значение играют информационно-коммуникационные технологии (ИКТ).

В ходе оценки влияния затрат на ИКТ на динамику некоторых макроэкономических параметров региональной экономики в качестве одного из параметров взят ВРП, а в качестве региональной экономики - Кабардино-Балкарская Республика. Анализ данных таблицы 1 позволил выявить то, что по объему затрат на ИКТ Кабардино-Балкария занимает ведущие позиции в СКФО [10].

Таблица 1

Соотношение динамики ВРП и затрат на ИКТ в КБР за 2010-2017 годы

\begin{tabular}{|l|c|c|c|c|c|c|c|c|c|c|c|}
\hline $\begin{array}{l}\text { ИН ДИКАТОРЫ/ } \\
\text { ПОК АЗ АТ ЛИ }\end{array}$ & 2010 год & 2011 год & 2012 год & 2013 год & 2014 год & 2015 год & 2016 год & 2017 год & $\begin{array}{c}\text { 2017 г г } \\
\text { од } \\
\text { к } \\
2010 \text { г } \\
\text { оду } \\
\text { негодо } \\
\text { вые } \\
\text { темпы } \\
\text { роста; } \\
\%\end{array}$ & $\begin{array}{c}\text { Коэф- } \\
\text { фициен } \\
\text { т вариа- } \\
\text { ции; \% }\end{array}$ \\
\hline ВРП, млн руб. & 77086,4 & 90594,5 & 106711,2 & 110971,5 & 116886 & 120528,8 & 132706,9 & 138524,3 & 179,7 & & 18,3 \\
\hline Цепные темпы роста; \% & 100 & 117,5 & 117,8 & 104,0 & 105,3 & 103,1 & 110,1 & 104,4 & & 108,7 & \\
\hline $\begin{array}{l}\text { Затраты на ИКТ, млн } \\
\text { руб. }\end{array}$ & 412,3 & 398,3 & 576,6 & 3717,4 & 452,6 & 1005,8 & 519,8 & 515,3 & 125,0 & & 119,5 \\
\hline Цепные темпы роста; \% & 100 & 96,6 & 144,8 & 644,7 & 12,2 & 222,2 & 51,7 & 99,1 & & 103,2 & \\
\hline $\begin{array}{l}\text { Доля затрат на ИКТ в } \\
\text { ВРП; \% }\end{array}$ & 0,53 & 0,44 & 0,54 & 3,35 & 0,39 & 0,83 & 0,39 & 0,37 & 69,6 & & 119,0 \\
\hline
\end{tabular}

*Источник: данные Росстата [9, 10].

Следовательно, объем средств, выделяемых на ИКТ, не устойчив, подвернут сильным колебаниям, периоды высоких затрат сменяются резким падением, и в целом за 2010-2017 годы наблюдается снижающая тенденция. При этом расчеты показывают на слабую корреляцию между затратами на ИКТ и ВРП. 
Созаева Т.Х., РаХаев Х.М., БакКУев Э.С.

ИНФОРМАЦИОННО-КОММУНИКАЦИОННЫЕ ТЕХНОЛОГИИ КАК ФАКТОР ПОВЫШЕНИЯ КОНКУРЕНТОСПОСОБНОСТИ РЕГИОНА

Таким образом, расчеты показали рост объема расходов на ИКТ в экономике КБР. В то же время эта динамика характеризуется высокой волатильностью, отсутствием устойчивых трендов и в целом высокой вариацией. Однако объем затрат на ИКТ не связан с показателями развития национального хозяйства в целом. Использование для этого показателя ВРП и оценка корреляции между ВРП и затратами на ИКТ по КБР показало наличие низкой связи - 0,040. Это может быть интерпретировано, как то, что расходы на ИКТ не связаны с ВРП. С другой стороны, внутри расходов на ИКТ наблюдается неравномерное и, на наш взгляд, нерациональное распределение этих расходов. Основную долю расходов занимают два направления: расходы на расходы на приобретение вычислительной техники и оргтехники и на приобретение телекоммуникационного оборудования. В общем объеме расходов доля данной группы в КБР составляет свыше $2 / 3$, а в целом по России - свыше $1 / 3$. Второе место занимают расходы на приобретение программного обеспечения $-5,8$ \%, в т. ч. по России в целом доля этой статьи в общих расходах составляет $17,4 \%$ [10].

Отметим, что по России расходы по данной статье уступают расходам на оплату услуг сторонних организаций и специалистов по ИКТ (кроме услуг связи и обучения) $-20,2 \%$. Доля данной статьи в КБР составляет чуть более 3,0 \%. Примечательно, что доля данной статьи в КБР снижается в отличие от общероссийской тенденции, где она растет. Важнейшей статьей расходов по ИКТ мы считаем расходы на обучение сотрудников, связанное с развитием и использованием ИКТ, что в КБР составляет $0,2 \%$, а в России $0,6 \%$ с явно выраженной тенденцией к снижению. Наряду с низким уровнем расходов на приобретение программных продуктов собственного производства, на наш взгляд, такая тенденция не стимулирует развитие внутреннего цифрового рынка.

Для цифровизации экономики особое значение имеет использование специальных программных средств, под которыми понимают «программные средства, используемые для решения задач определенного класса». Как правило, выделяют три типа задач: научные, обучающие и коммерческие. В статистике оценку данного сегмента проводят независимо от того, «разработаны ли эти программные средства собственными силами организации, приобретены у других разработчиков, выполнены по заказу сторонними фирмами или специалистами либо получены в пользование на иных условиях» [9]. В этом мы видим недостаток, т. к. не выделяются программные продукты, разработанные самими организациями, а также какой они юрисдикции. Все это вносит в статистические данные определенную «неразбериху», т. к. позволяет агентам различной юрисдикции относить эти продукты на свой счет, и, таким образом, рассчетно увеличивается объем данного сектора национального хозяйства. При этом в их составе не учитываются программные средства общего назначения, такие как операционные системы, компиляторы, стандартные программные средства. Такие, например, как текстовые или графические редакторы, электронные таблицы, системы управления базами данных и т. п. Правда, при одном условии, если на их основе не разработано специальное приложение, антивирусные программы, программы электронной почты и т. п. Как правило, такие программные продукты реализуются в виде пакета, который прилагается к компьютеру. Эти программные продукты являются продуктом определенных фирм и компаний, например Microsoft, «Лаборатория Касперского» и т. п. [5]. Но есть другие программные продукты, которые используются уже не для компьютера, а для решения так называемых побочных задач и не имеют прямого отношения к работе компьютера. Компьютер (вместе с программным продуктом для его работы) выступает в данном случае обычным счетным инструментом, который используется для решения конкретной задачи. В качестве таких программ выступают ERPсистема, CRM-система, SCM-система [11]. В 2010 году доля организаций, использовавших CRM, ERP, SCM - системы в общем объеме организаций КБР, составляла 7,5 \%. В целом по России этот показатель составлял 12,5 \%, т. е. в КБР показатель оказался ниже на 5 п. п.

Важным признаком развития цифровизации в экономике являются затраты на информационные и коммуникационные технологии. Понятное дело, что различные виды затрат носят разный характер в формировании архитектуры ИКТ экономики. И в этой связи нам представляется, что по удельному весу затрат (а также их объемам) можно судить о формируемой в экономике архитектуры ИКТ, а через нее и цифровой экономики в целом, т. е. создается ли самостоятельный сегмент (отрасль) экономики в национальном хозяйстве или же формируе- 
мый сектор ИКТ на самом деле выступает неким «отростком» чужой экономики в национальном хозяйстве.

Результаты. Проведенные исследования показали, во-первых, значимость оценки емкости рынка цифровой продукции и в целом цифрового рынка для развития национальной и региональной экономик. До настоящего времени нет однозначного ответа на то, как влияет цифровизация и цифровой рынок на динамику национального хозяйства, т. к. не разработаны критерии, показатели и методы оценки этого влияния. Во-вторых, до сих пор глубоких и специальных исследований емкости данного рынка у нас в стране ни на национальном, ни на региональном уровне не проводилось. В-третьих, не проводились исследования также рынка цифровой продукции в различных отраслях национального хозяйства. Все это сдерживает рациональное понимание самого рынка цифровой продукции. В настоящем исследовании предложены различные варианты в оценке емкости рынка цифровой продукции применительно для сельского хозяйства.

Выводы. Полагаем, что необходимо, во-первых, жестко привязать основные макроэкономические показатели развития региональных экономик в развитие цифрового рынка и его основных структур и элементов. Последнее делается с целью стимулирования цифровизации национального (регионального) хозяйства и расширения рынка в целом за счет включения в него нового цифрового продукта. Во-вторых, увеличить (причем кратно) расходы на ИКТ, а внутри данных расходов - по таким статьям, которые стимулировали бы развитие производства собственной цифровой продукции, а значит, развитие внутреннего цифрового рынка.

Литература

1. Азоев Г. Л. Методы оценки емкости рынка // Маркетинг и маркетинговые исследования в России. 1999. - № 6. - C. 43-48

2. Александровский С. В., Казанькова Н. В. Инструменты digital-маркетинга в практике микро-, малого и среднего бизнеса // Маркетинг и маркетинговые исследования. - 2015. - № 3. - С. 206-216.

3. Аубакирова Г. Цифровая трансформация экономики Казахстана //Проблемы теории и практики управления. - 2019. - № 2. - С. 18-26.

4. Белл Д. Социальные рамки информационного общества // Новая технократическая волна на Западе. - М.: Прогресс, 1986. - 342 c.

5. Кастельс М. Информационная эпоха: экономика, общество и культура / Пер. с англ. под науч. ред. О. И. Шкаратана. - М.: ГУ ВШЭ, 2000. 608 с.

6. Лопатников Л. И. Экономико-математический словарь. Словарь современной экономической науки. 5-е изд., перераб. и доп. - М.: Дело, 2003. - 520 с.

7. Основы маркетинга: Пер. с англ. / Котлер Ф., Армстронг Г., Сондерс Дж., Вонг В. - 2-е европ. изд. М.: СПб.; Киев: Вильямс, 1999. - 1151 с.

8. Портер М. Международная конкуренция: Конкурентные преимущества стран. - М.: Международные отношения, 1993. - 896 с.

9. Методологические пояснения к разделу 6 «Информационные и коммуникационные технологии» // Регионы России. Сочиально-экономические показатели. Стат. сб. / Росстат. - М., 2018. - С. 898.

10. Официальный сайт Федеральной службы государственной статистики Российской Федерации. [Электронный ресурс]. Режим доступа: http://www.gks.ru, свободный. - Загл. с экрана.

11. Рахаев Х. М., Мамбетова Ф. А., Созаева Т. Х. Состояние и некоторые тендениии в индустриализации экономики Северного Кавказа // Региональные проблемы преобразования экономики. - 2018. - № 12. - C. 140-149.

12. Рикардо Д. Начало политической экономии и налогообложения. Сочинения. Том I. - М.: Госполитиздат, 1955. - $360 \mathrm{c}$.

13. Саушкин Ю. Г. Введение в экономическую географию. - М.: МГУ, 1970. - 339 с.

14. Стратегия инновационного развития Российской Федерации на период до 2020 года: утверждена Распоряжением Правительства Российской Федераџии от 8 декабря 2011 г. - № 2227.

15. Указ Президента РФ от 9 мая 2017 г. № 203 «О Стратегии развития информациионного общества в Российской Федеращии на 2017-2030 годыл».

16. Уэбстер Ф. Теории информационного общества. - М.: Аспект Пресс, 2004. - 400 c.

17. Шваб К., Дэвис Н. Технологии Четвертой промышленной револющии: [перевод с английского] / Клаус Шваб, Николас Дэвис: Эксмо. - Москва; 2018. - 208 с.

18. Tapscott D. (1995). The Digital Economy: Promise and Peril In The Age of Networked Intelligence, mcgraw-Hill, 1995. 342 р. (русский перевод: Тапскотт, Д. Электронно-иифровое общество: Плюсы и минусы эпохи сетевого интеллекта / Пер. с анг. И.Дубинского; под ред. С.Писарева // Киев: INT Пресс; Москва: Релф бук, 1999. 432 с.).

References:

1. Azoev G. L. Metody ocenki emkosti rynka // Marketing i marketingovye issledovaniya v Rossii. - 1999. - № 6. - S. $43-48$

2. Aleksandrovskij S. V., Kazan'kova N. V. Instrumenty digital-marketinga v praktike mikro-, malogo i sredne- 
Coзafba T.X., РаХаев Х.М., БакКУев Э.С

ИНФОРМАЦИОННО-КОММУНИКАЦИОННЫЕ ТЕХНОЛОГИИ КАК ФАКТОР ПОВЫШЕНИЯ КОНКУРЕНТОСПОСОБНОСТИ РЕГИОНА

go biznesa // Marketing i marketingovye issledovaniya. - 2015. - № 3. - S. 206-216.

3. Aubakirova G. Cifrovaya transformaciya ekonomiki Kazahstana //Problemy teorii i praktiki upravleniya. 2019. - № 2. - S. 18-26.

4. Bell D. Social'nye ramki informacionnogo obshchestva // Novaya tekhnokraticheskaya volna na Zapade. M.: Progress, 1986. - 342 c.

5. Kastel's M. Informacionnaya epoha: ekonomika, obshchestvo i kul'tura / Per. s angl. pod nauch. red. O. I. SHkaratana. - M.: GU VSHE, 2000. 608 s.

6. Lopatnikov L. I. Ekonomiko-matematicheskij slovar'. Slovar' sovremennoj ekonomicheskoj nauki. 5-e izd., pererab. i dop. - M.: Delo, 2003. - 520 s.

7. Osnovy marketinga: Per. s angl. / Kotler F., Armstrong G., Sonders Dzh., Vong V. - 2-e evrop. izd. - M.: SPb.; Kiev: Vil'yams, 1999. - 1151 s.

8. Porter M. Mezhdunarodnaya konkurenciya: Konkurentnye preimushchestva stran. - M.: Mezhdunarodnye otnosheniya, 1993. - $896 \mathrm{~s}$.

9. Metodologicheskie poyasneniya $k$ razdelu 6 «Informacionnye i kommunikacionnye tekhnologii» // Regiony Rossii. Social'no-ekonomicheskie pokazateli. Stat. sb. / Rosstat. - M., 2018. - S. 898.

10. Oficial'nyj sajt Federal'noj sluzhby gosudarstvennoj statistiki Rossijskoj Federacii. [Elektronnyj resurs]. Rezhim dostupa: http://www.gks.ru, svobodnyj. - Zagl. s ekrana.

11. Rahaev H. M., Mambetova F. A., Sozaeva T. H. Sostoyanie i nekotorye tendencii v industrializacii ekonomiki Severnogo Kavkaza // Regional'nye problemy preobrazovaniya ekonomiki. - 2018. - № 12. - S. 140 -149 .

12. Rikardo D. Nachalo politicheskoj ekonomii i nalogooblozheniya. Sochineniya. Tom I. - M.: Gospolitizdat, 1955. $-360 \mathrm{~s}$.

13. Saushkin YU. G. Vvedenie v ekonomicheskuyu geografiyu. - M.: MGU, 1970. - 339 s.

14. Strategiya innovacionnogo razvitiya Rossijskoj Federacii na period do 2020 goda: utverzhdena Rasporyazheniem Pravitel'stva Rossijskoj Federacii ot 8 dekabrya 2011 g. - № 2227.

15. Ukaz Prezidenta RF ot 9 maya 2017 g. № 203 «O Strategii razvitiya informacionnogo obshchestva v Rossijskoj Federacii na 2017-2030 gody».

16. Uebster F. Teorii informacionnogo obshchestva. - M.: Aspekt Press, 2004. - $400 \mathrm{~s}$.

17. SHvab K., Devis N. Tekhnologii CHetvertoj promyshlennoj revolyucii: [perevod s anglijskogo] / Klaus SHvab, Nikolas Devis: Eksmo. - Moskva; 2018. - 208 s.

18. Tapscott D. (1995). The Digital Economy: Promise and Peril In The Age of Networked Intelligence, mcgraw-Hill, 1995. 342 p. (russkij perevod: Tapskott, D. Elektronno-cifrovoe obshchestvo: Plyusy i minusy epohi setevogo intellekta / Per. s ang. I.Dubinskogo; pod red. S.Pisareva // Kiev: INT Press; Moskva: Relf buk, 1999. 432 s.). 